\title{
Socotra Vegetation Database
}

\author{
Michele De Sanctis \& Fabio Attorre
}

\begin{abstract}
The Socotra Vegetation Database (GIVD ID AS-YE-001) contains 396 relevés (including 500 species). Ten percent of the relevés come from the scientific literature; the remaining $90 \%$ have been collected by the authors during several field campaigns carried out between 2007 and 2009. Phytosociological investigation was performed according to the methods described by Westhoff \& van der Maarel and Braun-Blanquet. The location of the relevé was selected in relation to the homogeneity of physical features, vegetation structure and species dominance. According to these criteria forest, woodland, shrubland, grassland and halophytic communities were sampled. Plot sizes ranged from $200 \mathrm{~m}^{2}$ to $4 \mathrm{~m}^{2}$ depending on the plant community. Cover/abundance data for all vascular plants were recorded in the field using the Braun-Blanquet scale. The database was created in TURBOVEG. A classification analysis was performed to identify the main vegetation communities of the islands and the results are included in the database.
\end{abstract}

Keywords: phytosociology; Socotra; TURBOVEG; Yemen.

\section{Socotra Vegetation Database}

Scope: Phytosociological relevés of the main vegetation communities of Socotra Island

Status: finished

Period: $1997-2010$

Database manager(s): Michele De Sanctis (michedes@gmail.com); Fabio Attorre (fabio.attorre@uniroma1.it)

Owner: Michele De Sanctis (private)

Web address: [NA]

Availability: according to a specific agreement

Database format(s): TURBOVEG

Publication: [NA]

Plot type(s): normal plots

Non-overlapping plots: 396

Total plot observations: 396

Online upload: no

Online search: no

Countries: YE: $100.0 \%$

Export format(s): TURBOVEG, MS Access, Excel

Forest: $21 \%$ - Non-forest: aquatic: $0 \%$; semi-aquatic: $0 \%$; arctic-alpine: $0 \%$; natural: $11 \%$; semi-natural: $67 \%$; anthropogenic: $0 \%$

Guilds: all vascular plants: $100 \%$

Environmental data: altitude: $80 \%$; slope aspect: $52 \%$; slope inclination: $52 \%$; soil depth: $65 \%$

Performance measure(s): cover: $100 \%$

Geographic localisation: GPS coordinates (precision $25 \mathrm{~m}$ or less): $75 \%$; point coordinates less precise than GPS, up to $1 \mathrm{~km}: 25 \%$

Sampling periods: $1990-1999: 5.0 \%$; 2000-2009: $85.0 \%$; 2010-2019: $10.0 \%$

Information as of 2012-07-12; further details and future updates available from http://www.givd.info/ID/AS-YE-001

Michele De Sanctis* (michedes@gmail.com), Fabio Attorre (fabio.attorre@uniroma1.it)

Environment Biology, Sapienza University of Rome, P.le Aldo Moro, 5, 00185 Rome, ITALY

*Corresponding author 